\title{
Removal of Silver from Aqueous Solution by Azotobacter chroococcum XU1 Biomass and Exopolysaccharide
}

\author{
Bakhtiyor A. Rasulovi,2, Abulimiti Yili², Haji Akber Aisa² \\ ${ }^{1}$ Institute of Genetics and Plant Experimental Biology, Uzbekistan Academy of Sciences, Yukory Yuz, Uzbekistan \\ ${ }^{2}$ The Key Laboratory of Plant Resources and Chemistry of Arid Zone, China Xinjiang Technical Institute of \\ Physics \& Chemistry, Chinese Academy of Sciences, Urumqi, China \\ Email: bakhtiyor1980@mail.ru
}

Received 25 February 2015; accepted 15 March 2015; published 24 March 2015

Copyright (C) 2015 by authors and Scientific Research Publishing Inc.

This work is licensed under the Creative Commons Attribution International License (CC BY).

http://creativecommons.org/licenses/by/4.0/

c) (i) Open Access

\begin{abstract}
Biosorption of silver ions onto A. chroococcum XU1 biomass and exopolysaccharide (EPS) was investigated. It was found that the overall biosorption process was the best when cell biomass and EPS were used together. Metal adsorption experiments showed that the final precipitate obtained by cell biomass and EPS, contained $7.85 \%$ of Ag. Based on the results presented in this study, the biomass and EPS of $A$. chroococcum XU1 indicated the possibility of application of them as biosorbent for removal of silver from waste waters.
\end{abstract}

\section{Keywords}

Azotobacter chroococcum, Biosorption, Silver, Cell Biomass, Exopolysaccharide

\section{Introduction}

Microorganisms and microbial products can be highly efficient bioaccumulators of soluble and particulate forms of metals, especially from dilute external solutions, and microbe-related technologies may provide an alternative or adjunct to conventional techniques of metal removal/recovery [1]. Heavy metals usually form compounds that can be toxic, carcinogenic or mutagenic, even in very low concentrations [2]. The conventional methods of removing metals from waste waters are generally expensive and have many limitations [3]. Alternative methods of metal removal and recovery based on biological materials have been considered. The use of biomass for the uptake of heavy metals has been extensively studied over last decade and it may represent an alternative for the existing technologies. A wide variety of microorganisms have been found to possess natural capability to se- 
quester heavy metals [1]-[3]. Besides, certain types of microbial exopolysaccharides (EPS) can adsorb relatively high quantities of metals by means of passive processes known as biosorption, which is dependent on the affinity between the metallic species or its ionic forms and the binding sites on the molecular structure of the microbial EPS [4] [5]. The employment of microbial EPS for the metal removal treatment of effluents is a perspective suggested by many researchers dealing with metal-EPS interactions. The presence on microbial EPS polarizable groups, such as carboxyl, hydroxyl and amino-groups [6], which are capable of interacting with cations, is responsible for their reversible metal binding capacity.

The present work investigates the potential use of Azotobacter chroococcum XU1 biomass and its exopolysaccharide as metal sorbent to remove silver from aqueous solutions. The resting cell of the strain has ability to adsorb silver ions, furthermore the EPS of this strain has a strong affinity to bind one valent metals, including silver. Application of Azotobacter chroococcum and its EPS as sorbent for silver removal has not been reported. In this article, the overall kinetics of silver biosorption is studied.

\section{Materials and Methods}

\subsection{Preparation of Sorbent (Biomass and EPS)}

Azotobacter chroococcum XU1 was cultivated at $30^{\circ} \mathrm{C}$ in $2 \mathrm{~L}$ flasks containing $1 \mathrm{~L}$ of Ashby medium (g. $\mathrm{l}^{-1}$ ): mannose, 20; $\mathrm{KH}_{2} \mathrm{PO}_{4}, 0.2 ; \mathrm{MgSO}_{4} \cdot 7 \mathrm{H}_{2} \mathrm{O}, 0.2 ; \mathrm{NaCl}, 0.2 ; \mathrm{K}_{2} \mathrm{SO}_{4}, 0.1 ; \mathrm{CaCO}_{3}, 5$, and shaken at $200 \mathrm{rpm}$ for 3 days with supply of sterile air.

\subsection{Production and Purification of EPS}

Upon completing the cultivation culture liquid was centrifuged at $6000 \mathrm{rpm}$ for $10 \mathrm{~min}$ for pelleting the bacterial cells and obtaining supernatants. EPS in the supernatant then precipitated adding cold ethanol in 1:2 (v/v). Precipitated EPS filtered out, dried and weighed [5].

\subsection{Effect of Carbon and Nitrogen Sources and Concentration on EPS Production by A. chroococcum XU1}

The effect of carbon source on the production of EPS was studied using Ashby medium supplemented with 1\% of glucose, sucrose, mannose and lactose. As nitrogen source there used peptone, tryptone, yeast extract, L-tryptophan, $\left(\mathrm{NH}_{4}\right)_{2} \mathrm{SO}_{4}, \mathrm{NH}_{4} \mathrm{NO}_{3}$ and $\left(\mathrm{NH}_{2}\right)_{2} \mathrm{CO}$, which were rich in nitrogen content.

Sucrose concentration in the growth medium varied from $0.25 \%$ to $3 \%$ in order to assess the effect of carbon concentrations on EPS production by Azotobacter chroococcum XU1. After 8 days, cells were removed by centrifugation at $6000 \mathrm{rpm}$ for $15 \mathrm{~min}$. The supernatant was passed through $0.2-\mu \mathrm{m}$-pore-size filter. Filtrate was dialysed against distilled water at $4^{\circ} \mathrm{C}$ to eliminate any low molecular weight sugars and salts using dialysis bags (MW cutoff of 8000). The dialysed supernatant was again concentrated using rotary vacuum evaporator at $40^{\circ} \mathrm{C}$ and adjusted to a known volume. A known aliquot was used to estimate EPS by the phenol sulphuric acid method.

\subsection{Metal Adsorption Experiments and Analysis}

The cell-free culture broth was added to metal solutions at optimized condition of $\mathrm{pH}$ at $25^{\circ} \mathrm{C}$. Two volumes of cold ethanol were added to the solutions. Then, the solution consisting of insoluble EPS was filtered through filter paper and the filtrate used for metal analysis. In order to account the effect of filter paper on adsorption of heavy metals, a separate set of control experiment was done with the same conditions for all experiments [5].

Total Ag in the sample was quantitatively determined by Inductively Coupled Plasma Atomic Emission Spectrometry (ICP-AES, Optima 2100DV, PerkinElmer, USA). All samples were analyzed in three replicates.

\subsection{Calculation of Adsorption and Isotherms Parameters}

The isotherms data were characterized by the Langmuir (1) and Freundlich (2) equations:

$$
C_{f} / q=\left(1 / q_{\max }\right) b+C_{f} / q_{\max }
$$




$$
q=K_{f} C_{f}^{1 / n}
$$

where $q$ is the metal uptake by polysaccharide $\left(\mathrm{mg} \cdot \mathrm{l}^{-1}\right), C_{f}$ is the equilibrium concentration of metal in solution $\left(\mathrm{mg} \cdot \mathrm{l}^{-1}\right),\left(b, q_{\max }\right)$ and $\left(K_{f}, n\right)$ are empirical constants of Langmuir and Freundlich isotherms respectively [5].

\section{Results and Discussion}

\subsection{Effect of Carbon and Nitrogen Sources on Biomass Formation and EPS Production}

In recent years, increasing attention has been paid on exopolysaccharides produced by several bacteria genera in particular Bacillus [4] [7], Azotobacter [5], Pseudomonas [8], Paenibacillus [9], Shewanella [10] and Methylobacterium [11]. It is interesting that most bacterial polysaccharides are characterized by the presence of uronic acids, pentoses, a polypeptide moiety or other nonsaccharide components, such as organic (e.g., acetyl, pyruvyl, succinyl group) or inorganic (e.g., sulphate or phosphate group) substituents [12] [13], have been documented for EPS synthesis, metal adsorption properties. But, little data exist on biomass and EPS utilization for metal removal treatments. Apart from EPS, microbial biomass also plays an important role in metal biosorption, as mentioned above [1]-[3]. In previous studies, A. chroococcum XU1 revealed high adsorption rate and played a major role in immobilization of heavy metals, such as $\mathrm{Hg}$ and $\mathrm{Pb}$ [5], but its biomass was not tested for heavy metals removal from aqueous solutions. For this purpose it was important to research biomass formation of the strain in different cultivation conditions.

Out of tested carbon and nitrogen sources mannose and L-tryptophan were the best substrates for biomass formation by A. chrooccoccum XU1. In these substrates the biomass yield was $3.2 \mathrm{~g}$ in mannose, $2.85 \mathrm{~g}$ in Ltryptophan (Table 1). In mannose and L-tryptophan EPS were produced up to 8.2 and $11.4 \mathrm{~g} / \mathrm{l}$ respectively. Therefore, these substrates were the best carbon and nitrogen sources for both biomass yield and EPS production.

\subsection{Effect of pH on Biosorption and Adsorption Kinetics}

Previous studies showed that the EPS of Azotobacter chrooccoccum XU1 was basically mannose containing [5] and in a crude form (when it obtained without heat treatment for protein inactivation) contained $3 \%$ of total protein. Adsorption of Ag ions was affected by $\mathrm{pH}$. It affected the solution chemistry of the metals, the activity of

Table 1. Cell biomass and EPS production by A. chrooccoccum XU1 on different carbon and nitrogen sources.

\begin{tabular}{ccc}
\hline Substrate & Cell biomass $(\mathrm{g} / \mathrm{l})$ & EPS production $(\mathrm{g} / \mathrm{l})$ \\
\hline Glucose & Carbon sources $^{*}$ & \\
Mannose & 1.67 & 7.2 \\
Sucrose & 3.2 & 8.2 \\
Lactose & 1.157 & 1.6 \\
& 0.305 & 1.0 \\
\hline Peptone & Nitrogen sources & \\
Tryptone & 2.67 & 8.5 \\
Yeast ext. & 2.18 & 7.8 \\
L-tryptophan $^{* *}$ & 2.42 & 8.2 \\
$\left(\mathrm{NH}_{4}\right)_{2} \mathrm{SO}_{4}$ & 2.85 & 11.4 \\
$\mathrm{NH}_{4} \mathrm{NO}_{3}$ & 2.3 & 7.8 \\
$\left(\mathrm{NH}_{2}\right)_{2} \mathrm{CO}$ & 2.1 & 7.6 \\
\hline
\end{tabular}

*For each variant the carbon sources were used in $20 \mathrm{~g} / \mathrm{l}$ amount; ${ }^{* * *}$ In these variants glucose was used as soul carbon source. 
functional groups in biopolymer, and the competition of metallic ions for biosorption [4]. In this study biosorption rates increase as $\mathrm{pH}$ of solution increases towards acidic. This may be due to interaction between cations and negative charges of acidic functional groups of polysaccharide. The decrease of biosorption at alkaline pHs might be attributed to start of insoluble hydroxide precipitating from solution at higher $\mathrm{pH}$ values, making true metal biosorption studies impossible [4].

The kinetics of adsorption of silver by Azotobacter chroococcum XU1 in tested samples was rapid during early minutes and levelled out after 20 min of metal solutions and supernatants mixing together at $25^{\circ} \mathrm{C}$. The kinetics of silver was rapider when both biomass and EPS were used together (Figure 1), than compared with biomass and EPS that were both taken alone.

Experiments confirmed that using both biomass and EPS of A. chroococcum XU1 enhanced silver removal from aqueous solutions. Similar results have been obtained by other authors [4] [5], where the adsorption kinetics reached its highest level in early minutes of mixing the metals solutions and bacterial products.

\subsection{Effect of Initial Concentration of Metal Ions on the Biosorption Capacity}

In biosorption, either live or dead microorganisms or their derivatives are used, which complex metal ions through the action of ligands or functional groups located on the outer surface of the cell, the metals may accumulate inside the cells, and/or the intrafibrillar capilarities of the cell walls by a combined sorption-microprecipitation mechanism [14]. Besides, a wide variety of secondary metabolites, such exopolysaccharides, proteins take part in binding the metals ions [6]. Taking into account that the metals can be adsorbed by the biomass and the secondary metabolites, it is important to determine the biomass' and the secondary metabolites' share in the biosorption process. On the other hand, colloidal systems like microbial cultures occur another chemical process - synthesis of silver nanoparticles in the presence of certain type of metabolites, like exopolysaccharides, proteins [5] [6]. Like other organic compounds, exopolysaccharides are able to reduce and stabilize the silver ions.

Current study shows that the presence of biomass of A. chroococcum XU1 and its EPS occur intensive biosorption and reduction of silver ions. Maximal efficiency of biosorption of the metal is observed in the presence of $15 \mathrm{mM}$ of $\mathrm{Ag}^{+}$and biomass and EPS of A. chroococcum XU1 (Figure 2).

As shown in Figure 2 biosorption activity of EPS and culture liquid (cell biomass and EPS) was the same until $5 \mathrm{mM}$ of $\mathrm{Ag}^{+}$, but further increasing the $\mathrm{Ag}^{+}$concentration, EPS alone was not able to adsorb the metal cations (in $0.71 \mathrm{~g} \mathrm{EPS} / 100 \mathrm{ml}$ supernatant). In this condition EPS alone formed the final precipitate with $2.4 \%$ of Ag. Silver adsorption patterns were affected by its initial concentrations, but it was obvious that the increasing trend would continue until the active adsorbing sites of EPS became saturated [15]. In the presence of cell biomass and EPS together (culture liquid) $\mathrm{Ag}^{+}$biosorption proportionally increased until $15 \mathrm{mM}$ of $\mathrm{Ag}^{+}$. In this concentration all Ag was biosorbed by cell biomass and EPS and obtained precipitate with 7.85\% Ag.

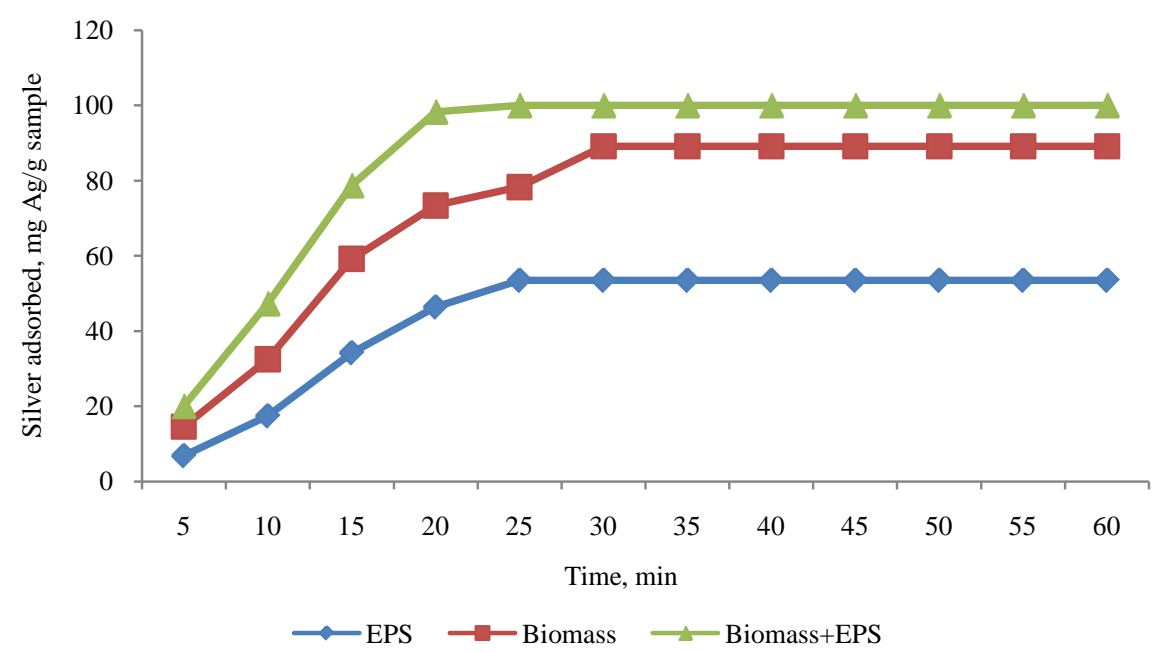

Figure 1. Time course of silver biosorption by biomass and EPS of $A$. chroococcum XU1. Initial silver concentrations were $100 \mathrm{mg} \cdot \mathrm{l}^{-1}$. 


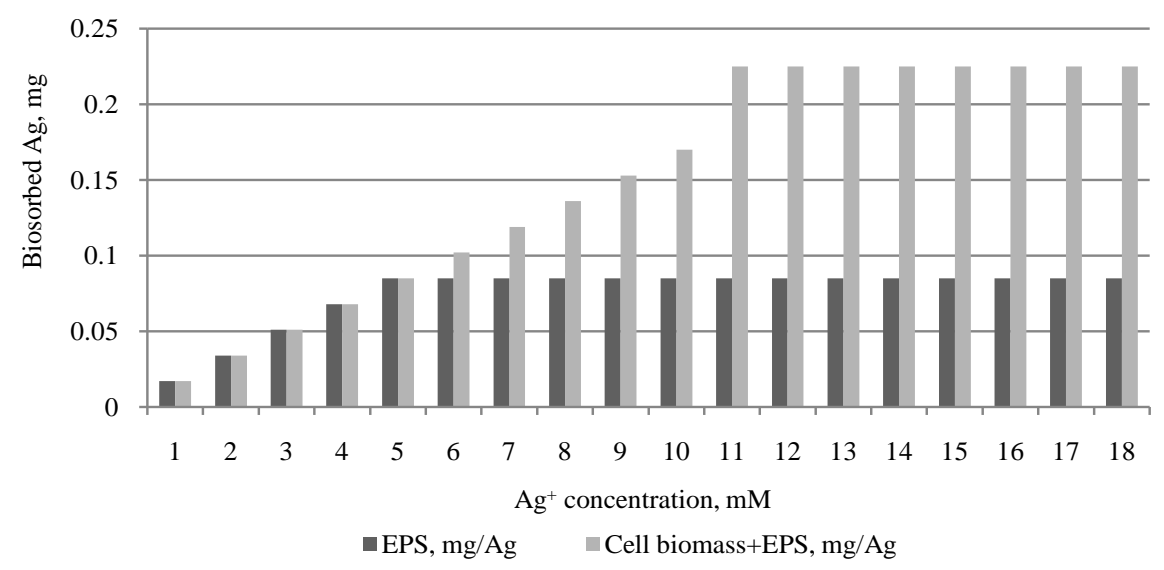

Figure 2. Biosorption of $\mathrm{Ag}^{+}$by EPS and cell biomass + EPS of $A$. chroococcum XU1.

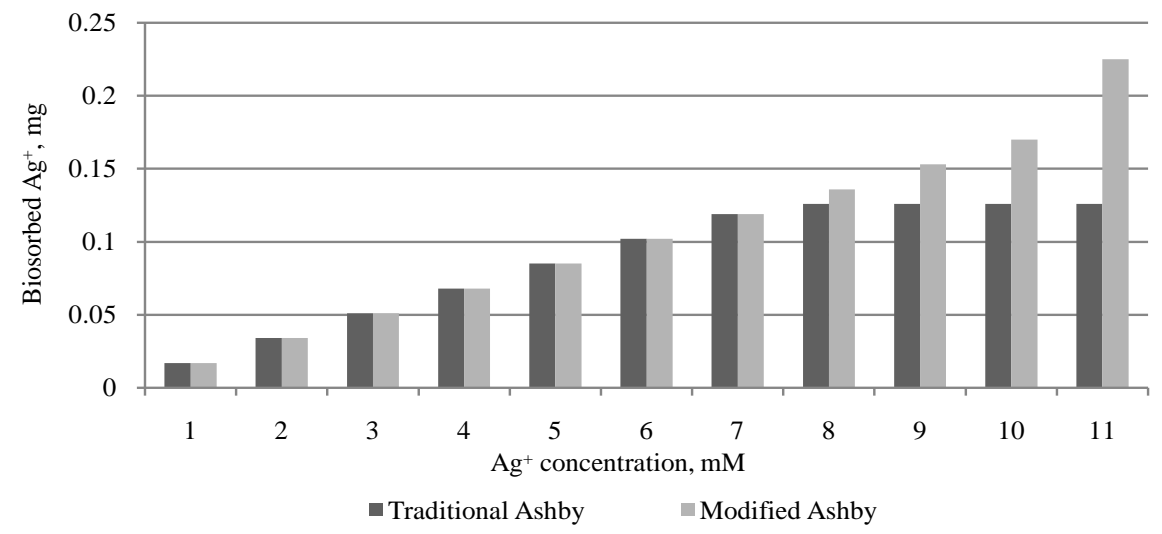

Figure 3. Difference in biosorption of $\mathrm{Ag}^{+}$by cell biomass + EPS of A. chroococcum XU1, obtained in traditional and modified Ashby medium.

It was obvious that the cell biomass of A. chroococcum XU1 together with EPS increased efficiency of biosorption on 2.64 times in comparing with when the EPS was used alone (Figure 2). The role of cell biomass and microbial EPS in the metals' removal was well documented in the literature and analogical data were reported [1]-[3] [16].

This work demonstrated increase of the metal removal efficiency via maximizing the cell biomass formation and enhancing the synthesis of EPS. In case A. chroococcum XU1, choosing ideal substrates for biomass formation and EPS production led to increasing the biosorption several folds. In comparing with biosorption of Ag by cell biomass of A. chroococcum XU1 and its EPS, it obtained in a modified Ashby to that of an ordinary Ashby, the efficiency of the metal removal increased on 1.78 times (Figure 3).

Current work is the first step to evaluate the role of biomass and EPS of Azotobacter chroococcum in removal of silver from aqueous solutions. Based on the results presented in this study, the cell biomass and EPS of Azotobacter chroococcum XU1 indicates the possibility of application of this biosorbent for removal of silver from waste waters, which affects environment.

\section{Acknowledgements}

This work was financially supported by grant of Drug R \& D Center of Central Asian, Chinese Academy of Sciences as well as Talents introduction and exchange from neighboring countries Program of Chinese Academy of Sciences.

\section{References}

[1] Simmons, P. and Singleton, I. (1996) A Method to Increase Silver Biosorption by an Industrial Strain of Saccharomyces 
cerevisiae. Applied Microbiology and Biotechnology, 45, 278-285. http://dx.doi.org/10.1007/s002530050684

[2] Singleton, I. and Simmons, P. (1996) Factors Affecting Silver Biosorption by an Industrial Strain of Saccharomyces cerevisiae. Journal of Chemical Technology and Biotechnology, 65, 21-28. http://dx.doi.org/10.1002/(SICI)1097-4660(199601)65:1<21::AID-JCTB382>3.0.CO;2-E

[3] Chen, C. and Wang, J.L. (2008) Characteristics of $\mathrm{Ag}^{+}$Biosorption by the Waste Biomass of Saccharomyces cerevisiae. Chinese Journal of Environmental Science, 29, 3200-3205.

[4] Salehizadeh, H. and Shojaosadati, S.A. (2003) Removal of Metal Ions from Aqueous Solution by Polysaccharide Produced from Bacillus firmus. Water Research, 37, 4231-4235. http://dx.doi.org/10.1016/S0043-1354(03)00418-4

[5] Rasulov, B.A., Yili, A. and Aisa, H.A. (2013) Biosorption of Metal Ions by Exopolysaccharide Produced by Azotobacter chroococcum XU1. Journal of Environmental Protection, 4, 989-993. http://dx.doi.org/10.4236/jep.2013.49114

[6] Kanmani, P. and Lim, S.T. (2013) Synthesis and Structural Characterization of Silver Nanoparticles Using Bacterial Exopolysaccharide and Its Antimicrobial Activity against Food and Multidrugresistant Pathogens. Process Biochemistry, 48, 1099-1106. http://dx.doi.org/10.1016/j.procbio.2013.05.011

[7] Martinez, R.E., Smith, D.S., Kulczycki, E. and Ferris, F.G. (2002) Determination of Intrinsic Bacterial Surface Acidity Constants Using a Donnan Shell Model and a Continuous $\mathrm{pKa}$ Distribution Method. Journal of Colloid and Interface Science, 253, 130-139. http://dx.doi.org/10.1006/jcis.2002.8541

[8] Borrok, D.M. and Fein, J.B. (2005) The Impact of Ionic Strength on the Adsorption of Protons, Pb, Cd, and Sr onto the Surfaces of Gram Negative Bacteria: Testing Non-Electrostatic, Diffuse, and Triplelayer Models. Journal of Colloid and Interface Science, 286, 110-126. http://dx.doi.org/10.1016/j.jcis.2005.01.015

[9] Morillo Perez, J.A., Garcia-Ribera, R., Quesada, T., Aguilera, M., Ramos-Cormenzana, A. and Monteoliva-Sánchez, M. (2008) Biosorption of Heavy Metals by the Exopolysaccharide Produces by Paenibacillus jamilae. World Journal of Microbiology and Biotechnology, 24, 2699-2704. http://dx.doi.org/10.1007/s11274-008-9800-9

[10] Claessens, J. and van Cappellen, P. (2007) Competitive Binding of $\mathrm{Cu}^{2+}$ and $\mathrm{Zn}^{2+}$ to Live Cells of Schewanella Putrefaciens. Environmental Science \& Technology, 41, 909-914. http://dx.doi.org/10.1021/es0620944

[11] Kim, S.-Y., Kim, J.-H., Kim, C.-J. and Oh, O.-K. (1996) Metal Adsorption of the Polysaccharide Produced from Methylobacterium organophilum. Biotechnology Letters, 18, 1161-1164. http://dx.doi.org/10.1007/BF00128585

[12] De Philippis, R. and Vincenzini, M. (1998) Exocellular Polysacharides from Cyanobacteria and Their Possible Applications. FEMS Microbiology Reviews, 22, 151-175. http://dx.doi.org/10.1111/j.1574-6976.1998.tb00365.x

[13] De Philippis, R., Sili, C., Paperi, R. and Vincenzini, M. (2001) Exopolysaccharide-Producing Cyanobacteria and Their Possible Exploitation: A Review. Journal of Applied Phycology, 13, 293-299. http://dx.doi.org/10.1023/A:1017590425924

[14] Aksu, Z. and Kutsal T. (1990) A Comparative Study for Biosorption Characteristics of Heavy Metals Ions with C. vulgaris. Environmental Technology 11, 979-987. http://dx.doi.org/10.1080/09593339009384950

[15] Lakzian, A., Berenji, A.R., Karimi, E. and Razavi, S. (2008) Adsorption Capability of Lead, Nickel and Zinc by Exopolysaccharide and Dried Cell of Ensifer meliloti. Asian Journal of Chemistry, 20, 6075-6080.

[16] Li, L., Hu, Q., Zang, J.H., Qi, H.Y. and Zhuang, G.Q. (2011) Resistance and Biosorption Mechanism of Silver Ions by Bacillus cereus Biomass. Journal of Environmental Sciences, 23, 108-111. http://dx.doi.org/10.1016/S1001-0742(10)60380-4 